\title{
OS MODELOS ESCOLARES NA PRIMEIRA REPÚBLICA EM MATO GROSSO
}

\author{
Laura Isabel Marques Vasconcelos de Almeida ${ }^{1}$ \\ Mariana Gomes de Oliveira²
}

\begin{abstract}
RESUMO: Este artigo tem como objeto de estudo os Regulamentos da Instrução Pública Primária de Mato Grosso, com o objetivo de analisar os documentos oficiais que retratavam os modelos escolares e as aspirações governamentais vigentes na Primeira República. Ancorada na dimensão metodológica da abordagem histórico-cultural, a pesquisa vincula-se ao grupo Ghemat Brasil. 0 percurso teórico-metodológico constitui-se por meio da narrativa acerca dos modelos escolares do período Imperial e Primeira República no Estado de Mato Grosso, a partir de fontes inventariadas no Instituto Memória e Arquivo Público: mensagens presidenciais, atas de exames e demais documentos produzidos nos anos finais do século XIX e início do século XX. O estudo aponta os elementos essenciais para compreensão do processo de historicização dos Regulamentos que determinavam as normativas para a Instrução Pública Primária do Estado de Mato Grosso e as fontes revelam os processos e dinâmicas que regulamentavam a organização pedagógica e disposição dos modelos escolares.
\end{abstract}

Palavras-chave: Modelos Escolares. Instrução Pública Primária. Primeira República.

\section{THE SCHOOL MODELS IN THE FIRST REPUBLIC IN MATO GROSSO}

ABSTRACT: This article has as object study the Regulations of the Primary Public Instruction of Mato Grosso, with the objective of analyzing the official documents that portrayed the school models and the governmental aspirations in force in the First Republic. Anchored in the methodological dimension of the historical-cultural approach, the research is linked to the Ghemat Brasil group. The theoreticalmethodological course is constituted through the narrative about the school models of the Imperial and First Republic period in the State of Mato Grosso, from sources inventoried in the Institute Memory and Public Archives: presidential messages, exam papers and other documents produced. The study points out the essential elements for understanding the process of historicization of the

\footnotetext{
1Doutora em Educação. Docente da Universidade de Cuiabá (Unic). Cuiabá-MT/Brasil. E-mail: lauraisabelvasc@hotmail.com

2 Mestre em Ensino. Docente da Universidade de Cuiabá (UNIC). Cuiabá-MT/Brasil. E-mail: marianagoliveira12@gmail.com
} 
Regulations that determined the rules for the Primary Public Instruction of the State of Mato Grosso and the sources reveal the processes and dynamics that regulated the pedagogical organization and the disposition of the school models. Keywords: School Models. Primary Public Education. First Republic.

\section{LOS MODELOS ESCOLARES EN LA PRIMERA REPÚBLICA EN MATO GROSSO}

RESUMEN: Este artículo tiene como objeto de estudio los Reglamentos de la Instrucción Pública Primaria de Mato Grosso, con el objetivo de analizar los documentos oficiales que retrataban los modelos escolares y las aspiraciones gubernamentales vigentes en la Primera República. La investigación se vincula al grupo Ghemat Brasil. El recorrido teórico-metodológico se constituye por medio de la narrativa acerca de los modelos escolares del período Imperial y Primera República en el Estado de Mato Grosso, a partir de fuentes inventariadas en el Instituto Memoria y Archivo Público: mensajes presidenciales, actas de exámenes y demás documentos producidos en los años finales del siglo XIX y principios del siglo XX. El estudio apunta los elementos esenciales para la comprensión del proceso de historización de los Reglamentos que determinaban las normativas para la Instrucción Pública Primaria del Estado de Mato Grosso y las fuentes revelan los procesos y dinámicas que regulaban la organización pedagógica y disposición de los modelos escolares.

Palabras clave: Modelos Escolares. Instrucción Pública Primaria. Primera República.

O presente artigo tem o desafio de apresentar fatos que ocorreram no passado e que possivelmente continuam sendo reproduzidos no presente. Enquanto pesquisadores faz-se necessário conhecer a historicidade dos aspectos políticos e educacionais de Mato Grosso para que possamos compreender os diversos fenômenos sociais que ocorrem na atualidade. De certo, podemos afirmar que nada adianta sermos meramente reprodutores de um processo educacional, e por vezes até assumirmos posição crítica, sem entendermos os motivos que determinaram o atual sistema educacional presente desde a educação primária até a educação superior.

Neste estudo, realizamos um breve apontamento acerca dos processos de escolarização ocorridos nos primeiros anos de escolarização em Mato Grosso, partindo da seguinte premissa: Quais eram os modelos escolares vigentes na Instrução Pública Primária matogrossense presentes na Primeira República? Na tentativa de responder à questão norteadora, nosso intento é compreender os processos que desencadearam o processo 
educacional que parece ter influenciado diretamente na legislação, na pedagogia, metodologia, nos investimentos de recursos públicos e criação de escolas, enfim, as estacas iniciais da Instrução Pública Primária no Estado de Mato Grosso, em especial dentro do período delimitado para o presente estudo, qual seja, final do século XIX e primeiros anos do século XX.

Considerando a legitimidade desses significados é que nos propomos a estudar essa problemática a partir da dimensão metodológica ancorada na abordagem histórico-cultural que se fundamenta nos aportes teórico e metodológico de historiadores mato-grossenses e autores renomados como: De Certeau (1982), Chervel (1990), Jacomeli (1998), Julia (2001), Leite (1970), Sá e Sá (2006), Silva (2006) e Valente (2003; 2015), que contribuem de forma peculiar por meio da narrativa que se constitui como metodologia para a compreensão do período escolar ocorrido há mais de um século e discutem o modo de fazer pesquisa com o ferramental indispensável para a escrita da historiografia da educação brasileira.

As fontes de pesquisa neste estudo se constituem a partir dos Regulamentos da Instrução Primária, mensagens presidenciais, resoluções, quadro de horário, conteúdos programáticos de disciplinas prescritos pela atividade administrativa estatal, edital, provas, atas de exames dentre outros documentos produzidos no período. Eles foram cuidadosamente inventariados para compreendermos a historicidade dos Regulamentos que determinavam as normativas para a Instrução Pública Primária do Estado de Mato Grosso e os processos e dinâmicas que regulamentavam a organização pedagógica e disposição dos modelos escolares.

Acerca do contexto político do período delimitado, o Estado de Mato Grosso, assim como todos os demais Estados da Federação, estava na transição do governo absolutista e arcaico representado pela coroa portuguesa (Período Imperial) para o governo republicano que defendia, em contraposição ao regime imperialista, os ideais libertários, que conferiu, aos entes da federação, liberdade de regulamentação própria, com a escolha de seus governantes e possibilidade de gestão de recursos. Nosso intento foi analisar os documentos oficiais e mensagens presidenciais (então governantes de Estado) do período, que aliados aos conceitos teóricos, permitiram realizar um retrato aproximado dos modelos escolares até então 
vigentes, as aspirações governamentais e, principalmente, os sucessos (ou insucessos) dos modelos aqui retratados.

Reconstruir a trajetória da educação mato-grossense no período da Primeira República é um desafio que possibilita questionar as similitudes de um período escolar de tempos de outrora. Isso permitiu situar o que mudou (ou não) especialmente em relação aos modelos escolares.

\section{Os modelos escolares matogrossenses na Primeira República: Escolas Elementares e}

\section{Complementares}

As diferenças regionais eram grandes e o Estado de Mato Grosso, no final do século XIX, sofria com a extensão territorial de proporções continentais, somadas ao fato da queda de exploração econômica e a distância geográfica significativa das grandes cidades do país. O quadro socioeconômico de Mato Grosso, nesse período, era um dos piores. Segundo os estudos de Jacomeli (1998), o estado atingiu forte queda de recursos econômicos em decorrência da queda da exploração de minérios, que teve início no ano de 1723 . A crise no ramo da mineração apresentou fortes impactos na arrecadação tributária do Estado e fortaleceu os índices de pobreza da população mato-grossense que, na época, era a única fonte econômica capaz de gerar recursos para a região.

Nesse cenário, a Primeira República ascendeu em nosso país e o Estado de Mato Grosso enfrentava toda ordem de escassez de recursos, o que ocasionou forte queda de arrecadação tributária, provocada diretamente pela Guerra do Paraguai, ocorrida entre os anos de 1865 a 1870, conforme destaca o relatório dos estudos de Jacomeli (1998), apresentado pelo Presidente Brigadeiro Alexandre Manoel A. de Carvalho à Assembleia Legislativa em agosto de 1865. O documento aponta que a Província de Mato Grosso passava por uma situação financeira desagradável:

O estado dos cofres públicos é bem desagradável. O exercício de 18631864, em liquidação, está devendo ao corrente de 1864-1865 a quantia de 67 contos por suprimentos que, lhe tem sido feitos, e no encerramento não poderá satisfazer o seu débito senão por meio de transação fictícia com o thesouro. Pela falta de fundos desse exercício e de promptos suprimentos do Thesouro, as suas despezas não forão sempre pontualmente pagas, chegando as do Corpo de Cavallaria a 
atrazar-se em cerca de seis mezes (Relatório do Presidente Brigadeiro Alexandre Manoel A. de Carvalho, 1866 apud JACOMELI, 1998, p. 48).

O documento explicita a realidade financeira que atravessava Mato Grosso, agravado pela Guerra do Paraguai que trouxe consigo os efeitos desastrosos: mortes pelo uso dos armamentos bélicos ${ }^{3}$, doenças para a população como a varíola e a contaminação dos soldados por doenças como a "bexiga de canudo" ${ }^{4}$ tornando-se responsáveis por dizimar boa parte da população da Província. A Instrução Pública Primária de Mato Grosso, a partir desse cenário de crise financeira, encontrava-se totalmente sem recursos para investimentos nos itens mais básicos, demonstrando a precariedade econômica do período retratado que refletia em todos os setores da sociedade, especialmente na educação.

Como reflexo da nítida ausência de investimento educacional, existiam em Mato Grosso poucas escolas seja no nível elementar, como também no nível complementar de ensino. Alves (1986, p. 41) afirma que:

Em Cuiabá havia três escolas particulares de primeiras letras e uma pública, além de uma aula de gramática latina, enquanto a aula de filosofia racional e moral encontrava-se desativada; Diamantino tinha uma única aula de gramática latina e Mato Grosso já não dispunha nem mesmo de uma escola de primeiras letras.

Outro ponto que merece destaque é que grande parte dos governantes anteriores à Primeira República relatava a ausência de qualificação dos professores para a Instrução Primária. As mensagens presidenciais de Augusto Leverger, Presidente da Província de Mato Grosso, revelam a ausência de conhecimento técnico e especialmente a carência de recursos humanos para qualificação dos professores da Instrução Primária.

\footnotetext{
${ }^{3}$ Entende-se por bélico todo o aparato utilizado para a guerra. Nessa época, os homens eram armados com instrumentos hábeis como as armas de fogo para fins de defesa do Estado de Mato Grosso durante o período da Guerra do Paraguai.

${ }^{4}$ Doença muito comum dos séculos XIX e XX correspondente à varíola que matou e deformou 300 milhões de pessoas entre 1896 e 1980. Causada pelo Orthopoxvirus variolae é considerada pela Organização Mundial de Saúde erradicada após campanha de vacinação em massa. O vírus era transmitido de pessoa para pessoa, geralmente por meio das vias respiratórias e também pelos objetos utilizados pela pessoa infectada. Após 14 dias de incubação, a doença começava a se manifestar e os primeiros sintomas eram: febre, mal-estar, fadiga, dores pelo corpo, manchas avermelhadas, vômitos e náuseas. As manchas avermelhadas que apareciam na pele se transformavam em bolhas purulentas que, após um período, secavam e formavam crostas popularmente chamadas de "bexiga de canudo"
} 
Não tive dúvidas em provar as cadeiras vagas em sujeitos que o exame havia mostrado pouca habilidade para regê-las; e até me pareceu nomear interinamente um candidato reprovado pelos examinadores, mas que não julguei menos idôneo do que os outros que estão regendo as aulas. [...] alguns professores mal sabem aquilo que devem ensinar. Contudo essa pouca instrução é preferível à ignorância absoluta (MARCílIO, 1963, p. 45).

Os documentos deixam claro que a falta de investimento afetava diretamente a Instrução Pública Primária, tendo reflexo direto na expansão da escolaridade e especialmente os cursos de qualificação para os professores que detinham pouco ou nenhum conhecimento para o preenchimento do cargo de Magistério. Fica evidenciado que a Instrução Pública da Província de Mato Grosso era precária, sendo que o referido fato era amplamente reconhecido pelos presidentes que antecederam o período republicano.

O cenário da instrução Pública Primária mato-grossense no período da Primeira República não era diferente de outras províncias do Brasil, apresentando problemas comuns em outras regiões do Brasil Império: situação de abandono, poucos recursos e ausência tanto de qualificação de professores, como também de estrutura física suficientemente adequada para atender a população. Cumpre lembrar o que diz Jacomeli (1998) sobre o contexto da educação no período:

As estruturas educacionais mato-grossenses, nas duas primeiras décadas da República, eram as mesmas herdadas do Império. Suas características podem ser resumidas: falta de professores habilitados; inexistência de cursos de formação de professores; reduzido atendimento às crianças em idade escolar; estrutura física e escassez de equipamentos e de materiais escolares (JACOMELI, 1998, p. 48).

As escolas, nesse período, eram confundidas como a extensão dos espaços residenciais em que, na grande maioria, as aulas eram ministradas em casas alugadas inadequadas para as atividades ou nas casas dos próprios professores, em decorrência da inexistência de prédios próprios para a realização das atividades escolares, sendo comum a confusão do ensino público em Mato Grosso como a extensão do ensino doméstico. A educação, conforme Reis e Sá (2006), dava-se da casa paterna para a escola (casa do mestre) ou vice-versa. Nesses termos, o espaço privado (da casa) cedeu lugar ao público (da escola ou da "da casa do mestre").

Foi nesse contexto que a Primeira República surgiu com os ideários de ordem e 
progresso, ecoando no país o objetivo principal da nação. Para que a República verdadeiramente se efetivasse, era necessário alcançar um povo que, consciente de seus direitos e deveres, pudesse exercer o sufrágio ${ }^{5}$, e por consequência, participar das escolhas de governo.

O ensino fundamentado em bandeiras liberais, como o sufrágio universal e formação do cidadão, eram as principais defesas do recém-proclamado Estado Republicano. Para que os ideários fossem concretizados, deveria ser instituída a obrigatoriedade do ensino e oferecida à população escolarizável visando à universalidade, em que a Instrução primária deveria ser pública e gratuita, sob a responsabilidade do governo.

No entanto, no período da Proclamação da República, no ano de 1889, o Brasil se encontrava com altos índices de analfabetismo. As províncias, até então subjugadas ao domínio do Império, mantinham uma instrução pública precária e praticamente inexistente em muitos lugares do território brasileiro, dentre eles, a Província de Mato Grosso.

A escola primária no período da Primeira República (final do século XIX e início do século XX) foi marcada por diversos fatores: a ausência de professores e corpo administrativo nas escolas; dificuldades de acesso dos alunos às escolas; escassez de materiais e principalmente os espaços escolares precários (SÁ, 2011). Diante desse cenário de instabilidade e precariedade, a Primeira República no Estado de Mato Grosso foi marcada por modelos escolares que surgiram por iniciativa governamental (edição de Resoluções e Regulamentos) com o objetivo de atender a população com idade escolarizável obrigatória. Nesse contexto, surgiram como alternativa para atender a população matogrossense as Escolas Singulares (oferecidas pela iniciativa pública e privada); os Grupos Escolares e as Escolas Reunidas.

O Regulamento Geral da Instrução Pública do Estado de Mato Grosso, de 1896, apresentou as prescrições oficiais no final do século XIX, permanecendo vigente até a primeira década do século XX. No entanto, em todos os mais de 350 artigos constam disposições diversas sobre a organização escolar durante os primeiros anos de escolarização da república no território mato-grossense.

50 direito ao voto, destinado a todos os indivíduos considerados intelectualmente maduros. 
O Regulamento determinou as modalidades escolares que seriam ofertadas no ensino público durante os primeiros anos de instrução, conforme o Artigo 2:

A instrucção primaria será dada em escolas denominadas elementares ou do primeiro gráo, e complementares ou do segundo gráo. Haverá escolas elementares em todas as cidades, villas, freguesias e povoados existentes no Estado, e complementares na capital e cidades principaes, devendo ser consideradas taes aquellas de maior desenvolvimento e densidade de população (MATO GROSSO, 1896b, p. 79).

No artigo 2ำ, o Regulamento destaca as duas modalidades de instrução: a Escola Elementar, destinada ao público de crianças com idade entre 7 a 10 anos e as Escolas Complementares, ofertadas aos maiores de 10 até o limite de 14 anos de idade. A Escola Elementar era considerada de frequência obrigatória e deveria funcionar em todos os lugares onde existissem cidades, vilarejos, povoados ou freguesias, ficando evidenciado que as Escolas Elementares tinham como objetivo a democratização do ensino aos infantes entre 7 a 10 anos, que representava para o período uma iniciativa inovadora.

As crianças entre a faixa etária de 7 a 10 anos somente poderiam ser dispensadas da frequência obrigatória da escola primária Elementar, quando comprovado pelos seus genitores o recebimento de instrução em casa; a criança apresentasse alguma doença ou limitação física incapacitante; e ainda, caso o infante residisse distante da escola. Consideravase a distância mínima de $1 \mathrm{~km}$ entre a casa do aluno e a escola, sendo referidos requisitos igualmente previstos nos artigos 4으 e 8o do Regulamento de 1896.

Por sua vez, as Escolas Complementares tinham por objetivo dar continuidade ao ensino ofertado pelas Escolas Elementares, mas o Regulamento não imputava a obrigatoriedade de frequência pelos alunos. Elas assumiram a função de formar alunos para o ingresso no Curso de Humanidades, oferecido somente pelo Liceu Cuiabano, localizado na Capital Cuiabá.

De acordo com o Regulamento, o Curso de Humanidades compunha o Ensino Secundário e admitia somente alunos acima de 14 anos, mediante realização prévia de um exame versando sobre as matérias constitutivas do Curso Complementar Primário, outrora 
estudado pelo candidato, conforme as normativas destacadas nos artigos 59 e seguintes do Regulamento de 1896. Embora com a ideia de universalização do ensino primário, o documento em estudo apresentava algumas exigências no que se referia à abertura de Escolas Singulares nas cidades do Estado de Mato Grosso. Com base nesse entendimento, seria possível a abertura das Escolas Elementares, somente quando na localidade houvesse um quórum mínimo de 20 alunos regulares e devidamente matriculados, sendo que não poderia ultrapassar o número de 60 alunos.

O controle dos quóruns mínimo e máximo era realizado pelo professor designado para o exercício da função docente e a escola, na maioria das vezes com estrutura precária, disponibilizava apenas uma sala de aula e um único professor para ministrar os conteúdos de todas as disciplinas aos alunos na faixa etária que compreendia entre 7 a 10 anos. A previsão do número mínimo de alunos fomentava a possibilidade de abertura desse modelo escolar em diversos povoados ou vilarejos mato-grossenses, que levava em consideração os baixos índices populacionais da época e a grande extensão territorial do Estado, necessitando a abertura de diversas Escolas Elementares, visando a facilitação de acesso pelas crianças em idade escolar obrigatória.

Em relação ao critério de quórum mínimo adotado à época, Leite (1970) fez ressalvas em a tal exigência, especialmente ao que se referia à população escolarizável que não seria atendida por escolas próximas a sua residência, conforme destacado:

Qual a situação daquelas crianças que vivessem em localidade de população infantil abaixo do mínimo exigido pelo regulamento? Se o ensino era obrigatório, essa obrigatoriedade estava sendo unilateral, quando ao contrário, tanto deviam ser obrigados os pais a mandar seus filhos às escolas como o Estado a levar instrução até eles! Os mesmos problemas criados pela baixa densidade demográfica de uma população que vivia em 1 milhão e meio de quilômetros quadrados. Tanto o Império como a República tiveram de lutar contra a fatalidade geográfica e outras dificuldades que os regulamentos não podiam resolver. Não se tratava, como aliás nunca se tratou, de simples mudança de regulamento (LEITE, 1970, p. 95).

Nos estudos de Leite (1970) é importante destacar que a restrição de abertura de novos espaços escolares, em decorrência da escassez de alunos - número inferior a vinte apresentava um contrassenso com os ideários republicanos tão propalados no período, 
especialmente no que se referia à universalização e obrigatoriedade do ensino. $O$ Regulamento de 1896 ainda viabilizava a possibilidade de abertura de escolas em espaços alugados, que na prática poderia ser a residência do professor, em função da ausência de prédios específicos para as atividades escolares nos vilarejos e povoados do Estado. Nesse contexto, faz-se necessário lembrar o disposto no artigo 18ㅇ destacado no documento.

Art. 18‥ Enquanto o Estado não dispuser de prédios para todas as escolas, abonará a cada professor uma quantia equivalente á metade do aluguel da casa em que funcionar a sua escola. Está quantia será fixada anualmente pelo Governo para cada localidade, sobre informação do Director Geral da instruç̧ão (MATO GROSSO, Decreto no 152, 1896a).

Entretanto, se de um lado havia certa facilitação na abertura de novos espaços escolares, e na prática representava ainda mais a precarização do ensino, de outro lado, a responsabilidade do exercício docente que ficava a cargo de um único professor. Além de responsável pela missão de ensinar, o professor deveria se preocupar com as questões vinculadas à administração da escola, considerando ainda que o espaço escolar era precário, singular e unitário, concentrando todas as funções da escola.

Nesse período, conforme destaca o Regulamento de 1896, as escolas deveriam ser fiscalizadas pelo Inspetor escolar e seus auxiliares. Além das inúmeras dificuldades de acesso às Escolas Elementares, que eram distantes da capital, os profissionais eram nomeados para um cargo sem nenhuma remuneração, ou seja, verdadeiro voluntariado à Instrução Pública Primária, que de certo modo inviabilizava a fiscalização efetiva dos espaços escolares.

Cumpre também destacar que o Regulamento apresentava o Programa de ensino que deveria ser seguido pela Escola Elementar e obedecido por todos os professores, conforme as seguintes disposições:

Art. 10. A escola elementar professa:

$\S 1$. Leitura corrente de impressos e manuscriptos.

$\S 2$ ㅇ. Calligraphia e escripta;

$\S 3$ 3․ Estudo pratico da língua materna;

$\S 4$ ㅇ. Exercício de intuição, ou noções de cousas acompanhadas de exercício de leitura e escripta e de explicações sobre formas, cõres, numeros, dimensões, tempo, sons, qualidade dos objectos, medidas, seu uso e applicação; 
$\S 5$ ㅇ. Arithmetica pratica até divisão por dous algarismos; problemas fáceis sobre as quatro operações; noções geraes sobre numeração e valores dos algarismos; grandeza, quantidade e unidade; comparação da grandeza com a unidade; consequências resultantes dessa comparação; generalidades sobre os modos de dividir e sobdividir a unidade; dividir especies de fracção resultantes de semelhante divisão.

$\S 6$. Cultura moral; commentario das narrativas dos livros de leitura e dos factos da vida escolar.

$\S 7$ 7․ Geografica física, e historia do Estado;

$\S 8$ ‥ Costura simples nas aulas de meninas (MATO GROSSO, Decreto no 152, 1896a).

Sobre os conteúdos a ensinar, o professor no período da vigência do Regulamento deveria se atentar para a utilização de materiais e livros didáticos com estampas, se dedicando aos exercícios mais práticos e atrativos para facilitar a aprendizagem do aluno. Cabia ainda, ao professor, ensinar de forma individual, não sendo permitido nenhum auxílio, sendo vedada a utilização do método mútuo ${ }^{6}$ de ensino. 0 método utilizado era o intuitivo, conforme destacado no Artigo 15

Art. 15. O professor se esforçará por tornar o ensino tão prático quanto possível, fazendo conhecer aos alunos os objetos, sua qualidade e organização, e partindo sempre de suas preleções do conhecido para o desconhecido e do concreto para o abstrato; deve-se abster-se de perturbar a inteligência da criança com o estudo prematuro de regras e definições, pondo, ao contrário, todo o empenho em amenizar o ensino, de modo a despertar a atenção do menino, sem fatiga-lo (MATO GROSSO, Decreto no 152, 1896a).

Embora fosse brilhante iniciativa, a proposta almejada durante o governo do Presidente do Estado Antônio Corrêa, não obteve resultados desejados. Eram necessárias muitas adequações, especialmente no tocante à capacitação dos professores que, para aplicar corretamente as disposições previstas na legislação, precisavam de instrução e orientação de como colocá-las em prática.

Leite (1970) ainda afirma que o governante do Estado, à época, tentava erigir uma escola a favor do aluno, que fosse um resumo vivo da sociedade, que preparasse homens de

6 Também conhecido como método Lancasteriano, visava suprir a falta de professores. Um aluno que se destacava podia ensinar os demais sob a orientação e supervisão de um único professor. 
acordo com suas particularidades, e não simplesmente, como máquinas reprodutoras de compêndios apreendidos de forma decorada e mecanizada. Essa situação gerou grande insatisfação social nos pais dos alunos e, principalmente, no futuro governante que viria a assumir a administração do Estado de Mato Grosso.

\section{As inovações da organização escolar: o Grupo Escolar e a Escola Normal em Mato} Grosso

Com o objetivo de consolidar na prática o método intuitivo prescrito no Regulamento de 1896, surgiram novos modelos escolares, com fulcro em novas organizações pedagógicas, e principalmente a ruptura do viés "doméstico" atribuído à Instrução Pública Primária. De todo o conjunto observado até aqui sobre os modelos escolares da Primeira República, é importante referendar a análise da Cultura Escolar no conceito definido por Julia (2001).

Cultura escolar é um conjunto de normas que definem conhecimentos a ensinar e condutas a inculcar, e um conjunto de práticas que permitem a transmissão desses conhecimentos e a incorporação desses comportamentos; normas e práticas coordenadas a finalidades que podem variar segundo as épocas (finalidades religiosas, sociopolíticas ou simplesmente de socialização). Normas e práticas, por sua vez, não podem ser analisadas sem se levar em conta o corpo profissional dos agentes que são chamados a obedecer a essas ordens e, portanto, a utilizar dispositivos pedagógicos encarregados de facilitar sua aplicação, a saber, os professores (JULIA, 2001, p. 10-11).

Nesse contexto, observa-se que o estudo da Cultura Escolar deve considerar todos os elementos valorativos, sejam eles internos ou externos, que contribuem para uma visão além dos limites da escola e desta forma possibilite a compreensão do pesquisador acerca da maneira de pensar dos atores envolvidos no processo de ensino e aprendizagem de um determinado período da escolarização.

Julia (2001) ainda esclarece sobre a delimitação do objeto de estudo das práticas escolares e, por sua vez, a compreensão exata da Cultura Escolar do período delimitado pelo pesquisador. Segundo o autor, deve-se considerar os resquícios documentais existentes, a produção do período, como: as leis, registros escolares, livros, dentre outros elementos disponíveis e acessíveis nos arquivos escolares.

Com base nos apontamentos de Julia (2001), compreende-se que, para obtermos 
conhecimento do período estudado, e consequente modelos escolares, faz necessária a análise de todos os documentos produzidos no período, o que nos possibilita a compreensão aproximada dos fatos ocorridos no âmbito escolar. Assim, visando aprimorar o ensino público oferecido gratuitamente pelo Estado e, com base nas dificuldades enfrentadas no desenvolvimento e progresso da Instrução Pública Primária, o novo Presidente do Estado, Pedro Celestino Corrêa da Costa, no ano de 1908, almejando alavancar o ensino com base nos ideários Republicanos de ordem e progresso, no início de seu governo, ampliou o número de Escolas Isoladas oferecidas no Estado de Mato Grosso que representavam 42 unidades existentes, ampliando de forma significativa para 104 unidades singulares em apenas um ano de governo.

Por meio da Resolução no 08, de 16 de outubro de 1908, Pedro Celestino, criou também oficialmente os Grupos Escolares com objetivo de trazer cisão ao modelo das escolas singulares tidas como instituições familiares e ineficientes, sugerindo que os Grupos Escolares serviriam como medida de inovação na Instrução Pública, sendo reconhecidos como escolas graduadas, seriadas ou centrais. Reis e Sá (2006) afirmam nos seus estudos que os Grupos Escolares apresentavam um programa enciclopédico de acesso obrigatório e universalizado, sendo que a organização oficial desse modelo ocorreu somente com a promulgação do Regulamento de 1910, que igualmente, apresentou uma nova organização para as modalidades escolares até então desenvolvidas na Instrução Pública.

O novo Regulamento trazia como ideia basilar a reunião das escolas singulares em um só prédio, o que justificou a adoção da terminologia "grupos escolares", que sugere em definitivo, a criação de edifícios próprios para a atividade escolar obrigatória. A Lei no 580 destaca as quantidades necessárias para formação de Grupos Escolares: mínimo de 3 e no máximo 8 Escolas Isoladas. Sobre a definição dos Grupos Escolares, o professor Leowigildo Martins de Mello assim pontuou.

O grupo escolar é um curso primário, seriado em quatro classes distintas para ambos os sexos. Por essas classes, primeira, segunda, terceira e quarta distribuem-se gradativamente, os conhecimentos que constituem a instrução primária, propriamente dita. As matérias ensinadas da primeira à quarta classe obedecem a um plano uniforme, de tal natureza que o educando, ao iniciar o seu curso na primeira 
classe, recebe conhecimento dosado pedagogicamente, de todas as disciplinas consagradas no programa geral do Grupo Escolar. O Grupo Escolar apresenta uma uniformidade perfeita em suas aulas e impossibilita completamente o desenvolvimento maior de uns em prejuízos de outros conhecimentos (REIS; SÁ, 2006, p. 40).

O documento aponta que as escolas apresentavam dois graus: 1 ㅇ e 20 e deveriam ser estabelecidas em todas as cidades e vilarejos do Estado de Mato Grosso, devendo ser divididas conforme o sexo, sendo que, as escolas do sexo feminino deveriam ser regidas por professoras e as do sexo masculino, por professores. No que se refere aos conteúdos a serem ministrados, o Regulamento de 1910 prescreve, em seu artigo 4으, que as escolas de 10 Grau deveriam trabalhar: Leitura, escrita; Cálculo aritmético sobre números inteiros e frações; Língua materna; Geografia do Brasil; Deveres cívicos e morais e trabalhos manuais apropriados à idade e ao sexo dos alunos. Para os alunos que iriam frequentar o 2 Grau, os professores deveriam seguir as mesmas disciplinas do 1으 grau, porém, acrescentando: gramática elementar da Língua Portuguesa, leitura de prosa e verso, escrita sob ditado e caligrafia; Aritmética até regra de três, sistema legal de pesos e medidas, morfologia geométrica; Desenho a mão livre; Moral prática e Educação cívica; Geografia geral e História do Brasil; Cosmografia, noções de Ciências Físicas, Químicas e Naturais; Leitura de música e canto, tudo conforme previsto nas prescrições oficiais.

Em relação ao ensino em sala de aula, a orientação era igualmente prevista no Regulamento de 1896: ser prático e intuitivo, devendo o professor durante o desenvolvimento das lições, iniciar do conhecido para o desconhecido; do concreto para o abstrato, e evitar ao máximo o estudo enfadonho de regras e definições previamente fechadas e se esforçar para instigar a mente criativa dos alunos. Para atuar nesse novo modelo escolar, fez-se necessário preparar os professores e, a partir dessa necessidade, a criou-se a Escola Normal. Com a formação da primeira turma, as vagas nos Grupos Escolares foram devidamente ocupadas pelos professores normalistas, atendendo em parte as reais necessidades do ensino público (SÁ, 2011).

Vale ressaltar que, nesse período, as Escolas Isoladas continuaram em atuação em paralelo aos Grupos Escolares. Nesse contexto, foram necessárias diversas mudanças no antigo modelo para fins de contenção de gastos como: a extinção da Escola Complementar 
por não compor a frequência obrigatória; a graduação do ensino com a instauração de um Programa escolar idêntico a dos Grupos Escolares, e ainda, a organização do tempo (quadro de horários) escolar, sob a administração singular do professor em sala de aula, que continuava tendo que lidar com alunos de faixa etária diferente.

\section{As Escolas Reunidas}

As Escolas Reunidas, consideradas como a última modalidade escolar do período da Primeira República, foram criadas com o objetivo de reduzir gastos, otimizando recursos físicos e materiais, sendo que poderiam ser unificadas 7 (sete) turmas distintas em apenas um prédio, sob a responsabilidade de uma única administração escolar, podendo ser exercida por um professor que igualmente receberia gratificação pelos serviços prestados. As condições para criação das Escolas Reunidas foram delineadas com o Regulamento de 1927, que assim designava: localização de até $2 \mathrm{~km}$, onde estivessem em funcionamento pelo menos três ou mais escolas isoladas com no mínimo 80 alunos matriculados e com frequência regular e limite máximo de 7 classes. No que se refere ao regimento interno, seria aplicado o mesmo direcionado aos Grupos Escolares.

As Escolas Reunidas no Estado de Mato Grosso foram uma sugestão do professor Waldomiro Campos, então diretor do Grupo Escolar de Poconé/MT, no ano de 1916, que vislumbrando a necessidade de unificação das escolas, percebeu a necessidade de reunir as escolas singulares, como forma de prenúncio dos Grupos Escolares. Vale destacar que o Regulamento de 1927 criou a nova modalidade de reunião de escolas e igualmente classificou as demais, conforme apresenta o Quadro 1.

Quadro 1 - Nova Modalidade de Escolas

\begin{tabular}{|l|l|}
\hline Escolas Isoladas Urbanas & \multicolumn{1}{|c|}{ As localizadas até $\mathbf{3}$ km da sede do munícipio; } \\
\hline Escolas Isoladas Noturnas & $\begin{array}{l}\text { Idênticas às anteriores, destinadas aos meninos maiores de } \\
12 \text { anos que não podiam frequentar cursos durante o dia; }\end{array}$ \\
\hline Grupos Escolares & $\begin{array}{l}\text { Deveriam compreender no mínimo } 8 \text { (oito) classes, e seriam } \\
\text { criadas quando houvesse, no mínimo, um raio de } 2 \mathrm{~km}, 250 \\
\text { (duzentos e cinquenta) crianças em idade escolar. }\end{array}$ \\
\hline
\end{tabular}

Fonte: LEITE (1970, p. 143) com adaptações

Os quóruns mínimos de criação igualmente eram previstos no Regulamento que apresentava diferenciação de público mínimo em conformidade com cada classificação, ou 
seja, para as escolas Isoladas Rurais, deveria, por exemplo, ter pelo menos (trinta) crianças em idade escolar para sua criação.

\section{Considerações finais}

Os modelos escolares vigentes no Estado de Mato Grosso, no período dos primeiros anos de escolarização da Primeira República, eram semelhantes ao período de transição entre as Escolas Isoladas e os Grupos Escolares. A intenção dos governantes e administradores da Instrução Pública do período já aspirava por alterações substanciais no modelo escolar vigente, que apresentava precariedades em diversas áreas, desde a formação docente até a estrutura física dos espaços escolares, conforme afirmam autores da história do ensino matogrossense.

O modelo das Escolas Isoladas representava um contraponto aos ideários republicanos de ordem e progresso que na maioria não eram institucionalizadas. Utilizavam métodos de repetição dos conteúdos e não dispunham da supervisão dos inspetores escolares, que sequer compareciam para fiscalizar, em decorrência da ausência de remuneração para o exercício do cargo.

Os Regulamentos analisados indicam que os três modelos escolares das primeiras décadas do período republicano deixam clara a intenção do poder público e da legislação em oferecer à população matogrossense, especificamente aos Grupos Escolares e às Escolas Reunidas, um modelo escolar eficiente, organizado e homogêneo, porém, o que se observa, era um grande percentual de professores que não tinham formação necessária para o exercício da docência almejada, cabendo-Ihes, ainda, a tarefa de assumir a responsabilidade pela administração e pelo trabalho pedagógico das Escolas Isoladas que, por sua vez, eram distantes da capital e consideradas ineficientes e desorganizadas.

No entanto, os modelos e organizações escolares tornam-se um objetivo a ser conquistado pelos governantes responsáveis pela regulamentação do ensino na época. Mesmo com dificuldades de investimento e precariedade nas condições de trabalho, os órgãos mantenedores idealizaram um ensino previsto nas prescrições oficiais que, na prática, por conta de vários entraves não conseguiram consolidar conforme almejavam.

As análises ainda revelam que as exigências de número mínimo de alunos frequentes 
nos espaços escolares, em especial as Escolas Isoladas, acrescidos da ausência de recursos suficientes destinados para o desenvolvimento da Instrução Pública, conforme as aspirações governamentais, evidenciam que o ensino dos infantes na primeira década do século XX não conseguia atender satisfatoriamente os preceitos republicanos de ensino gratuito e obrigatório para as crianças. As fontes também apontam que de nada adiantava a publicação dos Regulamentos, se na prática não ocorresse uma ação sincronizada entre recursos para a educação e capacitação dos professores responsáveis pelo ensino da população escolarizável.

Os mesmos males que vinham dos tempos imperiais persistiam no período da Primeira República pelos mesmos motivos que perduraram ao longo dos anos, pela falta de mestres qualificados, pelo descrédito da escola pública pela sociedade (em especial, os pais das crianças), e principalmente pela ausência de recursos para a construção de prédios adequados que pudessem atender a população mato-grossense.

\section{Referências}

ALVES, Gilberto Luiz. Fatos e Fitas da Instrução em Mato Grosso: um pouco de nossa memória educacional. Revista MS Cultura, Campo Grande, ano 2, n. 6, p. 41-47, jul/ago/set. 1986.

DE CERTEAU, Michel. A escrita da história. Rio de Janeiro, RJ: Forense Universitária, 1982.

CHERVEL, André. História das disciplinas escolares: reflexões sobre um campo de pesquisa. Porto Alegre, Teoria e Educação, n. 2, p. 177-229, 1990.

JACOMELI, Mara Regina Martins. A Instrução Pública Primária em Mato Grosso na Primeira República: 1891-1927. 1998. 191f. Dissertação (Mestrado em Educação) - Universidade Estadual de Campinas, Campinas, SP, 1998.

JULIA, Dominique. A cultura escolar como objeto histórico. Revista Brasileira de História da Educação, Campinas, n. 1, p. 9-43, jan/jun. 2001.

LEITE, Gervásio. Um século de instrução pública: história do ensino primário em Mato Grosso. Goiânia/GO: Rio Bonito, 1970.

MARCILIO, Humberto. História do ensino em Mato Grosso. Cuiabá: Secretaria de Educação, Cultura, e Saúde, 1963.

MATO GROSSO. Decreto Lei no 152 de 16 de abril de 1896a. Instituto Memória da Assembléia Legislativa do Estado do Mato Grosso.

MATO GROSSO. Regulamento da Instrução Pública, 1896b. Instituto Memória da Assembléia Lesgislativa do Estado de Mato Grosso. 
MATO GROSSO. Regulamento da Instrução Pública, 1910. Arquivo Público do Estado de Mato Grosso.

MATO GROSSO. Regulamento da Instrução Pública, 1927. Arquivo Público do Estado de Mato Grosso.

REIS, Rosinete Maria dos; SÁ; Nicanor Palhares de. Palácio da Instrução: institucionalização dos grupos escolares em Mato Grosso (1910-1927). Cuiabá: Central de Texto; EdUFMT, 2006.

SÁ, Elizabeth Figueiredo et al. (org). A escola pública primária mato-grossense no período republicano (1900-1930). Revisitando a história da escola primária: os grupos escolares em Mato Grosso na primeira república. Cuiabá, MT: EdUFMT, 2011.

SÁ, Nicanor Palhares; SÁ, Elizabeth Figueiredo de. A escola pública primária mato-grossense no período republicano (1900-1930). Revisitando a história de escola primária: os grupos escolares em Mato Grosso na Primeira República. Cuiabá-MT: EdUFMT, 2011

SILVA, Elizabeth Figueiredo de Sá Poubel e. Escola Normal de Cuiabá: história de professores em Mato Grosso (1910-1916). In: SÁ, Nicanor Palhares de; SIQUEIRA, Elizabeth Madureira (org.). Coleção coletânea educação e memória. Cuiabá -MT: Central do Texto, EdUFMT, 2006. v. 3

VALENTE, Wagner Rodrigues. No tempo das provas orais: subsídios para a história da educação matemática no Brasil. Anais da XI CIAEM. Blumenau-SC: FURB, 2003.

VALENTE, Wagner Rodrigues. A constituição do elementar matemático: uma análise de programas de ensino - São Paulo (1890-1950). Educação Unisinos (Online), v. 19, n. 2, p. 196-205, 2015.

Recebido em: 21/02/2018

Aprovado em: 09/05/2019 